\title{
Successful Non-Invasive Treatment of Stricturing Fibrosing Colonopathy in an Adult Patient
}

\author{
G. Terheggen ${ }^{1}$, D. Dieninghoff ${ }^{2}$, E. Rietschel ${ }^{2}$, U. Drebber ${ }^{3}$, W. Kruis ${ }^{4}$, L. Leifeld ${ }^{4}$ \\ ${ }^{1}$ Department of Medicine, Evangelisches Krankenhaus Duesseldorf, Duesseldorf, Germany \\ ${ }^{2}$ CF-Center, Children's Hospital, University of Cologne, Cologne, Germany \\ ${ }^{3}$ Institute of Pathology, University of Cologne, Cologne, Germany \\ ${ }^{4}$ Department of Internal Medicine, Evangelisches Krankenhaus Kalk, Cologne, Germany
}

\begin{abstract}
Objective: Fibrosing colonopathy (FC) is a rare entity associated with cystic fibrosis (CF). Until now, patients with stricturing FC have usually been treated surgically. In this instance, we aimed at avoiding surgery by applying a new conservative approach.

Methods: Case report on an adult with CF who developed persistent abdominal pain due to a non-passable stricture in the right transverse colon. Histology confirmed fibrosing colonopathy.

Results: Initially we treated the patient with prednisolone pulse therapy and additive antibiotic therapy. For maintenance therapy we administered budesonide. The patient underwent clinical, laboratory and endoscopic follow-up over a three-year period. The stricture healed and was easy to pass. A relapse in the cecum at the ileocecal valve again improved under steroid and antibiotic therapy.

Conclusions: We present a novel therapeutic approach for advanced stricturing FC in an adult patient which successfully avoided surgery (right hemicolectomy) over a three year follow up.
\end{abstract}

Key words: fibrosing colonopathy; cystic fibrosis; colonic stricture

\section{CASE REPORT}

A 25-year-old man suffering from pre-existing cystic fibrosis was admitted with persistent pain in the right lower-quadrant. He reported a history of meconium ileus at birth, appendectomy and recurrent distal intestinal obstruction syndrome (DIOS). His genotype (compound heterozygote $\Delta \mathrm{F} 508 / \mathrm{R} 553 \mathrm{X}$ ) is associated with pancreatic insufficiency [1]. Throughout childhood he was substituted with high-strength pancreatic enzymes (pancreatin 150.000 units/d). During adolescence he took pancreatin 10.000 units for fat-rich nutrition only. On his first presentation in July 2007, the patient reported about a 20 -month history of recurrent pain in the right lower abdominal quadrant which now had increased dramatically. Under intake of laxatives he had had daily bowel movements without visible blood. On admission he appeared in good physical condition with a stable body weight (BMI $22.2 \mathrm{~kg} / \mathrm{m}^{2}$ ) and physical examination revealed focal tenderness in the right-lower quadrant and normal bowel sounds. Laboratory values showed an elevated C-reactive protein $(10.7 \mathrm{mg} / \mathrm{dl}$ ) and a slight anemia (hemoglobin: $10.6 \mathrm{~g} / \mathrm{dl})$. Transabdominal ultrasound demonstrated hypoechoic bowel wall thickness of the transverse colon $(10 \mathrm{~mm})$ and a $30 \mathrm{~mm}$ long stricture in the right transverse colon (Fig. 1). The bowel wall of the ascending colon and cecum was mildly thickened, while no abnormalities could be observed in the terminal ileum. Colonoscopy was incomplete because of a nonpassable circular stricture in the right transverse colon (Fig. 1). Distal of the stricture the colonic mucosa appeared hyperemic, edematous and ulcerated for about $20 \mathrm{~cm}$. The remaining left-sided colon did not show any abnormalities. The histopathologic examination of the endoscopic biopsies showed ulcerative inflammation, cryptitis, irregular hyperplasia of goblet cells, submucosal fibrosis and disruption of the muscularis mucosa consistent with the diagnosis of fibrosing colonopathy (Fig. 1). After the patient had given his informed consent with regard to the experimental character of the therapy we initiated intravenous prednisolone pulse therapy $(75 \mathrm{mg} / \mathrm{d})$ for 10 days followed by a slow dose tapering $(10 \mathrm{mg} /$ week to $25 \mathrm{mg}$, than $5 \mathrm{mg}$ /week) over 10 weeks. In addition, we administered intravenous antibiotic therapy (mezlocillin $6 \mathrm{~g} / \mathrm{d}$, metronidazole $1 \mathrm{~g} / \mathrm{d}$ ). The patient's symptoms improved significantly and C-reactive protein levels decreased. After 3 weeks control-colonoscopy showed healed ulcerations. Furthermore, the stricture had healed with some minor scars remaining and could now be passed allowing a view on the ascending colon and cecum. Here we found multiple pseudopolyps and a lack of haustration while the terminal ileum appeared normal. Histologically, FC with residual inflammation was confirmed. For maintenance therapy we administered budesonide $9 \mathrm{mg} / \mathrm{d}$. Half a year later the patient presented without any abdominal pain and increasing body weight. He had further decreased the dosage of budesonide to $6 \mathrm{mg} / \mathrm{d}$ by himself. Colonoscopy showed an unchanged status. Therapy with budesonide $6 \mathrm{mg} / \mathrm{d}$ was continued.

However, in January 2009, 18 months after his first admission, the patient once more presented with crampy pain in the right lower abdominal quadrant. While the region of the former stricture in the right 


\begin{tabular}{|c|c|c|}
\hline & Prior to treatment $07 / 2007$ & After treatment $03 / 2011$ \\
\hline $\begin{array}{l}\text { Abdominal } \\
\text { ultrasound }\end{array}$ & $\begin{array}{l}\text { Hos os? c6 } \\
\text { Hypoechoic bowel wall thickening (10mm) } \\
\text { of the transverse colon, unremarkable } \\
\text { bowel wall of the ascending colon and a } \\
\text { stricture of nearly 30mm length }\end{array}$ & - \\
\hline Colonoscopy & $\begin{array}{l}\text { Non-passable circular stricture in the right } \\
\text { transverse colon with ulcerative inflamma- } \\
\text { tion }\end{array}$ & 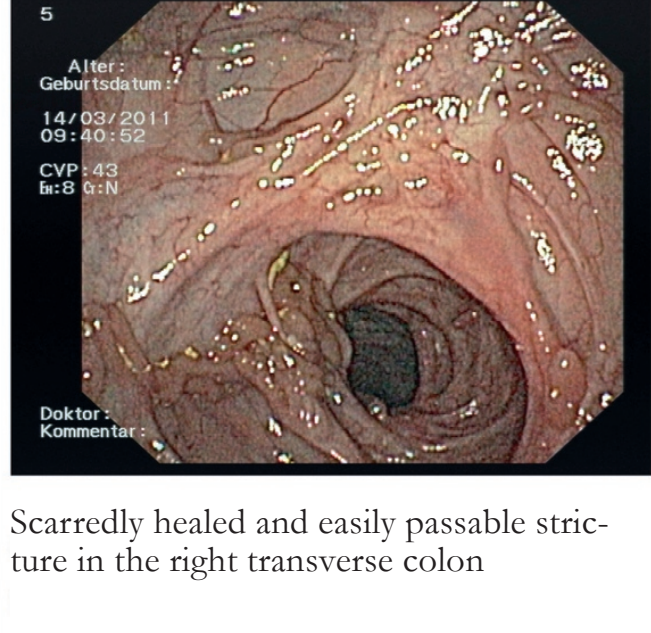 \\
\hline Histology & $\begin{array}{l}\text { Sor } \\
\text { Colonic biopsy with hypercellular lamina } \\
\text { propria with lymphocytes, eosinophilic } \\
\text { granulocytes, ulcerative inflammation, ar- } \\
\text { chitectural distortion of the crypts and sub- } \\
\text { mucosal fibrosis }\end{array}$ & $\begin{array}{l}\text { Colonic biopsy with regenerative epitheli- } \\
\text { um, mucosal edema and lymphocytic infil- } \\
\text { trate in the lamina propria }\end{array}$ \\
\hline
\end{tabular}

Fig. 1.

transverse colon was unremarkable, we now found areas of ulcerative inflammation in the cecum and at the ileocecal valve which could not be passed due to inflammatory stenosis. As during the first episode we treated the patient with prednisolone pulse therapy and antibiotics with again good clinical response and administered budesonide $9 \mathrm{mg} / \mathrm{d}$ for maintenance therapy. In July 2009, colonoscopy demonstrated that 
the stricture in the right transverse colon was now healed and easy to pass. In the cecum multiple pseudopolyps without additional inflammation were found. The ileocecal valve was constricted over a very short distance and nearly passable with the colonoscope.

Finally after more than three years, in March 2011 the patient presented in an excellent physical condition with stable weight under maintenance therapy. The colonoscopy showed an unchanged status (Fig. 1).

\section{Discussion}

Fibrosing colonopathy is a rare entity associated to patients with CF. It has generally been reported in young children approximately 12 months after exposure to high dose pancreas enzyme supplementation (HDPE). The exact etiopathogenesis still remains unsolved. Predisposing factors are young age (2-13 years), history of gastrointestinal complications (DIOS, meconium ileus), previous intestinal surgery, HDPE and use of histamine H2-receptor blockers, corticosteroids or recombinant human deoxyribonuclease (DNase) [2]. To our knowledge, only five cases of $\mathrm{FC}$ in adults were reported [3-7]: three patients with $\mathrm{CF}$, one developed FC after HDPE in pancreatic insufficiency and one suspicious of Crohn's disease and treated with mesalazine. Interestingly, development of FC in these five adults was not clearly associated with HDPE: two patients developed FC under treatment with HDPE, one patient after discontinuation of HDPE and two without HDPE at any time. All of these patients were symptomatic due to strictures and the diagnosis of FC was discovered during surgery.

Clinical symptoms are usually those of intestinal obstruction with abdominal pain, constipation or diarrhea and hematochezia. Abnormal bowel wall thickness is a common finding in CF, but it is usually not associated with clinical features and is no predisposing factor for FC [8, 9]. Endoscopy may demonstrate a friable, hyperemic, edematous, stiff or ulcerated mucosa often with strictures, colonic shortening and loss of haustration. FC usually spares the rectum and may be either segmental, mostly in the right colon, or involves the complete colon. Characteristic histologic features include submucosal fibrosis, disruption of the muscularis mucosa, ulcerative inflammation, eosinophilia and cryptitis [10-13]. In contrast, in ulcerative colitis common features are an acute and chronic inflammatory cell infiltrate, distortion of crypts, crypt abscesses and goblet cell depletion. The differentiation to stricturing Crohn`s disease can be challenging in the absence of characteristical epitheloid granuloma.

To our knowledge this is the first report of a nonpassable colonic stricture in FC which was successfully treated without surgical intervention. Treatment was based on an antiinflammatory concept with prednisolone pulse therapy. Additional antibiotic therapy aimed at treating bacterial translocation due to barrier dysfunction of the intestinal mucosa. In order to avoid side effects of longterm systemic steroids treatment was continued with topical active budesonide. However, maintenance therapy with budesonide did not protect the patient from a second stenosis at the cecum. If clinical symptoms from this stenosis should accelerate in the future, balloon dilatation of the ileocecal valve or a limited surgical intervention might be the treatment of choice. Analogue to Crohn's disease maintenance therapy with thiopurins might be another experimental option. However, until now we avoided the risk of long-term immunosuppression due to the fear of bronchopulmonary infections in CF. Body weight (BMI $25 \mathrm{~kg} / \mathrm{m}^{2}$ ) and physical condition improved under therapy with budesonide. Interestingly, lung function improved remarkably under therapy demonstrating an increase of forced expiratory volume in one second (FEV1) from $67 \%$ to $93 \%$ which may point to a relationship between the inflammatory status of the bowel and pulmonary affection in CF. According to the current guidelines we recommended a pancreatic enzyme supplementation on demand which should not exceed 10.000 units of lipase per $\mathrm{kg}$ per day [14, $15]$.

In conclusion, this case demonstrates a non-passable colonic stricture in FC which was discovered endoscopically and was successfully treated conservatively over a three-year period. This suggests a new therapeutic approach in CF patients with stricturing FC.

Conflict of interest: For all authors no conflicts of interest exist.

\section{REFERENCES}

1. The Cystic Fibrosis Genotype-Phenotype Consortium. Correlation between genotype and phenotype in patients with cystic fibrosis. N Engl J Med. 1993;329:1308-13

2. FitzSimmons SC, Burkhart GA, Borowitz D, et al. Highdose pancreatic enzyme supplements and fibrosing colonopathy in children with cystic fibrosis. N Engl J Med. 1997;336:1283-9

3. Häusler M, Meilicke R, Biesterfeld S, Heimann G. First adult patient with fibrosing colonopathy. Am J Gastroenterol. 1998;93:1171-2

4. Mack EH, Brett AS, Brown D. Fibrosing colonopathy in an adult cystic fibrosis patient after discontinuing pancreatic enzyme therapy. South Med J. 2004;97:901-4

5. Franzen D, Went P, Buhlmann U. Fibrosing colonopathy in absence of pancreatic enzyme supplementation in one adult patient with cystic fibrosis. Indian J Gastroenterol. 2008;27:133-4

6. Bansi DS, Price A, Russell C, Sarner M. Fibrosing colonopathy in an adult owing to over use of pancreatic enzyme supplements. Gut. 2000;46:283-5

7. Gaia E, Sambatoro A, De Giuli P, Angeli A. Adult fibrosing colonopathy associated with mesalazine treatment. Am J Gastroenterol. 2001;96:2508-9

8. Haber HP, Benda N, Fitzke G, et al. Colonic wall thickness measured by ultrasound: striking differences in patients with cystic fibrosis versus healthy controls. Gut. 1997;40:406-11

9. Dialer I, Hundt C, Bertele-Harms RM, Harms HK. Sonographic evaluation of bowel wall thickness in patients with cystic fibrosis. J Clin Gastroenterol. 2003;37:55-60

10. Reichard KW, Vinocur CD, Franco M, et al. Fibrosing colonopathy in children with cystic fibrosis. J Pediatr Surg. 1997;32:237-41

11. Schwarzenberg SJ, Wielinski CL, Shamieh I, et al. Cystic fibrosis-associated colitis and fibrosing colonopathy. J Pediatr. 1995;127:565-70

12. Dodge JA. The aetiology of fibrosing colonopathy. Postgrad Med J. 1996;72(suppl 2):S52-5 
13. Lloyd-Still JD, Beno DW, Kimura RM. Cystic fibrosis colonopathy. Curr Gastroenterol Rep. 1999;1:231-7

14. Lloyd-Still JD. Cystic fibrosis and colonic strictures. A new "iatrogenic" disease. J Clin Gastroenterol. 1995;21: $2-5$

15. Stevens JC, Maguiness KM, Hollingsworth J, et al. Pancreatic enzyme supplementation in cystic fibrosis patients before and after fibrosing colonopathy. J Pediatr Gastroenterol. Nutr 1998;26:80-4
Received: April 1, 2011 Accepted: May 17, 2011

Address for correspondence:

Dr. med. G. Terheggen

Kirchfeldstr. 40

40217 Duesseldorf

Germany

Phone: +49-211-919-0

E-mail: grischa.terheggen@evk-duesseldorf.de 